\title{
Fabrication and Characterization of New $\mathrm{Ti}^{-\mathrm{TiO}_{2}-\mathrm{Al}}$ and $\mathrm{Ti}^{-\mathrm{TiO}_{2}}$-Pt Tunnel Diodes
}

\author{
Yaksh Rawal, Swaroop Ganguly, and Maryam Shojaei Baghini \\ Department of Electrical Engineering, IIT-Bombay, National Center for Photovoltaic Research and Education (NCPRE), \\ Mumbai 400076, India \\ Correspondence should be addressed to Yaksh Rawal, yakshr@ee.iitb.ac.in
}

Received 6 January 2012; Accepted 13 February 2012

Academic Editor: Junseok Chae

Copyright ( 2012 Yaksh Rawal et al. This is an open access article distributed under the Creative Commons Attribution License, which permits unrestricted use, distribution, and reproduction in any medium, provided the original work is properly cited.

Remotely empowered wireless sensor networks use different energy resources including photovoltaic solar cells, wireless power transmission, and batteries. As another option the electromagnetic energy available in the ambient can be harvested to power these remote sensors. This is particularly valuable if it is desirable to harvest the ambient energy available in the wide range of electromagnetic spectrum. This has motivated the research for developing energy harvesting devices which can absorb this energy and produce a DC voltage. Rectenna, an antenna coupled with a rectifier, is the main component used for absorbing electromagnetic radiation at $\mathrm{GHz}$ and $\mathrm{THz}$ frequencies. Rectifying MIM tunnel diodes are able to operate at tens and hundreds of $\mathrm{GHz}$ frequency. As the preliminary steps towards development of high-frequency rectifiers, this paper presents fabrication and DC characterization of two new $\mathrm{MIM}$ diodes, $\mathrm{Ti}_{-} \mathrm{TiO}_{2}-\mathrm{Al}$ and $\mathrm{Ti}-\mathrm{TiO}_{2}-\mathrm{Pt}$. $G-V$ analysis of the fabricated diodes verifies tunneling. Brinkman-Dynes-Rowell model is used to extract oxide thickness of which the derived value is around $9 \mathrm{~nm}$. Ti-TiO 2 - $\mathrm{Pt}$ diode exhibits rectification ratio of 15 at $0.495 \mathrm{~V}$, which is more than rectification ratio reported in earlier works.

\section{Introduction}

Recently electromagnetic collectors are being explored as one of possible means of harvesting ambient energy, available in the wide range of solar spectrum [1]. RF energy harvesting is a special case of this broad approach [2-4]. This kind of energy can be used for low-power applications such as remote powering of sensors; charging mobile phones and laptops anywhere. Electromagnetic waves, received by an antenna, are converted into DC voltage with the help of highfrequency rectifiers, filters, and voltage multipliers. The heart of the rectifier is the diode. This diode can be a Schottky diode or a metal-insulator-metal (MIM) tunnel diode. The Schottky diode has limitations such as long reverse recovery time, and hence it cannot provide faithful rectification at high frequencies. MIM tunnel diode works on the principle of quantum mechanical tunneling. More often antenna and rectifier element are integrated as one component, called rectenna. Brown from Raytheon Company, for the first time used the term "rectenna" for rectifying-antenna, which was invented to absorb the microwave radiation and simultaneously convert it to DC power [5]. In 1964, he demonstrated a microwave powered helicopter which lasted for 10 hours with the helicopter hovering at an altitude of $60 \mathrm{ft}$. In 1972 Bailey proposed a new concept, called electromagnetic wave energy converter (EWEC), using unique pyramidal solar radiation absorber-converter elements [6]. Hoofring et al. have reported the fabrication and characterization of thin film metal-oxide-metal tunnel diodes for the use in far-infrared rectenna [7]. Recently, the Clean Energy Research Center, University of South Florida, has reported harvesting energy of infrared radiations from solar energy $[8,9]$. They have also reported application of MIM tunnel diodes in millimeter wave detection [10]. Millimeter wave imaging systems are the next generation of imaging systems being developed for security and surveillance purposes.

Importance of developing MIM diodes for future highly efficient rectenna is the motivation behind the research presented in this paper. The paper presents fabrication flow 
and DC characterization of two new MIM diodes, $\mathrm{Ti}^{-\mathrm{TiO}_{2}-}$ $\mathrm{Al}$ and $\mathrm{Ti}-\mathrm{TiO}_{2}-\mathrm{Pt}$. Brinkman-Dynes-Rowell $G-V$ model is used to extract the oxide thickness, which is calculated around $9 \mathrm{~nm}$. Behavior of native and plasma oxide devices is compared. $\mathrm{Ti}-\mathrm{TiO}_{2}-\mathrm{Pt}$ diode exhibits rectification ratio of 15 at 0.495 , which is more than rectification ratios reported in earlier works [11].

\section{Fabrication of MIM Tunnel Diodes}

Figure 1 shows the process flow for native oxidized sample (left) and plasma oxidized sample (right). The top electrode was deposited by the shadow mask technique. The squares of sizes 200 microns, 100 microns, and 50 microns were deposited. Two different fabrication techniques are used to form $\mathrm{TiO}_{2}$ : native oxide growth and plasma oxidation. This section explains details of the process flow for both techniques. Diagrams of both process flows shown in Figures 1 (a) and 1(b) show the structure of MIM tunnel diode and its microscopic top view image.

2.1. Fabrication Flow for Native $\mathrm{TiO}_{2}$ Growth. A silicon wafer is used as a substrate for the MIM stack. The bottom layer of the metal is titanium, which is sputtered by RF sputtering at $150 \mathrm{~W}$ forwarding power up to a thickness of $70 \mathrm{~nm}$. The sample is kept in class 1000 clean room for not more than a week to form a native titanium dioxide on it. Then the top electrode is formed by the thermally evaporating aluminum up to a thickness of $150 \mathrm{~nm}$ at base pressure of $3.5 \times 10^{-6}$ mbar. Another sample is made in which the top electrode is evaporated with platinum using electron beam evaporation at base pressure of $3 \times 10^{-6}$ mbar. The deposition of the top electrode is done with the help of shadow mask which has the squares of the sizes 200 microns, 100 microns, and 50 microns. Titanium can readily be oxidized, forming a native oxide when exposed to the oxygen in the air for some time. This fact is used to get the native oxide on the titanium and the selection of counter electrode to get the work function difference.

2.2. Fabrication Flow for Plasma Oxidized Ti. The alternate method for the titanium dioxide formation which can be highly controlled is plasma oxidation. Titanium is deposited by electron beam evaporation up to a thickness of $80 \mathrm{~nm}$ and then exposed to the oxygen plasma for 30 seconds. The forwarding RF power to form the plasma is $1500 \mathrm{~W}$, and the standard oxygen flow in the chamber is $3000 \mathrm{sccm}$. The Applied Materials Etch Centura is used for the plasma oxidation. Other recipes were also tried by exposing the titanium for 15 seconds and also 15 and 30 seconds variant with RF power of $1000 \mathrm{~W}$. The only sample that was working was the plasma oxidation, performed at $1500 \mathrm{~W}$ for 30 seconds. Oxygen flow is kept constant at $3000 \mathrm{sccm}$, which is minimum value to sustain the oxygen plasma. The kinetics of the native oxide formation has been thoroughly explained by Mott [12-14] and Cabrera and Mott [15]. The kinetics of plasma oxidation has been explained by Adrianus with respect to magnetic tunnel junctions [16].

\section{Characterization of MIM}

The MIM tunnel diode is characterized using semiconductor characterization system from Keithley probe station 4200SCS. Both the contacts are made from the top. The $\mathrm{Al}$ or Pt mesas are contacted from the top and the bottom electrode of $\mathrm{Ti}$ is contacted by little scratching through the thin oxide formed on the surface. The current density versus voltage plot for the MIM diode with native oxide is shown in Figure 2. Figure 3 shows the current density versus voltage plot for the MIM with plasma oxidized titanium dioxide. The higher current density of Figure 3 can be explained by the higher work function difference between titanium and platinum electrodes and the small area of the devices. The better quality of plasma oxidized titanium dioxide over native oxide of titanium is also a reason for higher current density.

The $d I / d V=I^{\prime}$ is the conductivity of the MIM diode. The rate of change of conductivity is defined as $d^{2} I / d V^{2}=I^{\prime \prime}$. The ratio of the second derivative of current and the first derivative of current is called the sensitivity of the MIM diode, $S=I^{\prime \prime} / I^{\prime}$. This ratio defines the nonlinearity of the diode and hence the diode performance. The first derivative of current defines the rate of change of the conductance and hence the asymmetry. Figure 4 shows the maximum sensitivity of the diode measured at room temperature, which is $18 \mathrm{~V}^{-1}$ at dc voltage of $0.09 \mathrm{~V}$. This is good as compared to $15 \mathrm{~V}^{-1}$ obtained by Krishnan [11]. The $d I / d V$ plot for the native oxide and plasma oxide of titanium dioxide MIM is shown in Figures 5 and 6, respectively.

According to Brinkman et al., the plot of conductivity $(d I / d V)$ versus voltage will be a parabola [17]. The asymmetry in the parabolic curve is due to the difference between work functions of the metal electrodes used for MIM device. Therefore, similar to forward and reverse biasing of diodes if the applied voltage to the electrode with lower work function is more than the applied voltage to the electrode with higher work function, the MIM diode will be forward biased. As Figures 5 and 6 show, the conductivity is higher in forward-biased region, compared to reversebiased region of two MIM diodes. Shape of conductivity parabola is not same for two diodes since one of them uses $\mathrm{Pt}$ and $\mathrm{Ti}$ for electrodes and the other one uses $\mathrm{Al}$ and $\mathrm{Ti}$ for electrodes. The coefficients of the fitted parabola were used to extract the thickness of the dielectric, which was found to be $9 \mathrm{~nm}$ for native oxide and plasma oxide. The current density versus voltage and the conductivity versus voltage plots for both native titanium and plasma oxide were observed. The asymmetry in the conductivity accounted for the work function difference of the dissimilar metal electrodes. Brinkman et al. (BDR fit) [17] gave the equation for the conductivity of the metal-insulator-metal diode as

$$
\frac{G(V)}{G(0)}=1-\left(\frac{A_{0} \Delta \varphi}{16 \bar{\varphi}^{3 / 2}}\right)(q V)+\left(\frac{9 A_{0}^{2}}{128 \bar{\varphi}}\right)(q V)^{2}
$$



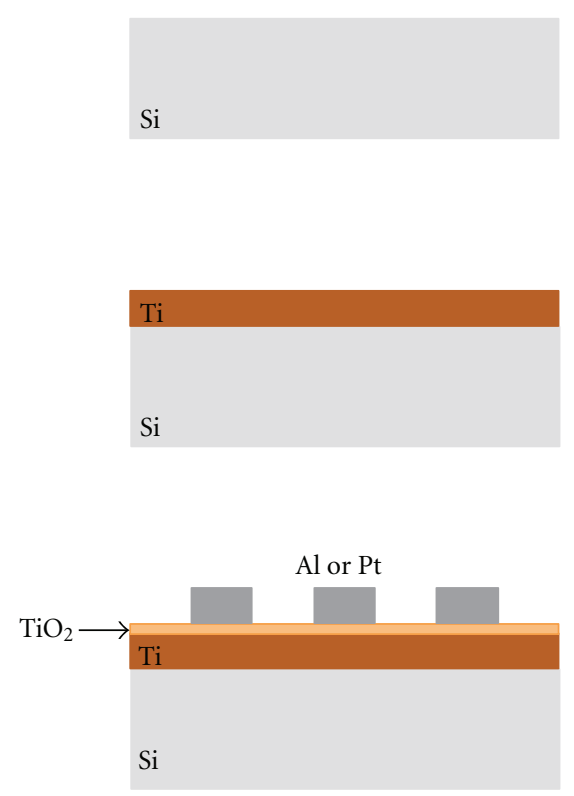

(a)

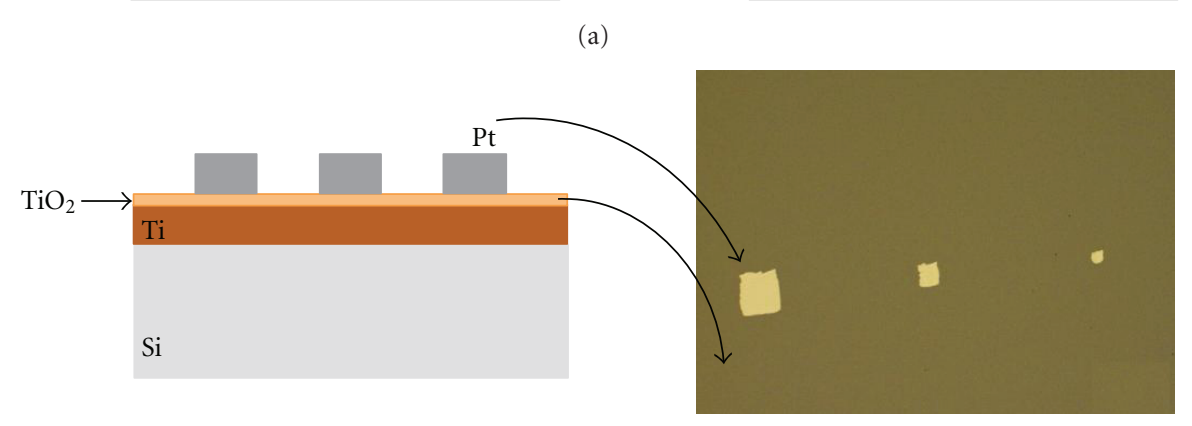

(b)

$\mathrm{Si}$
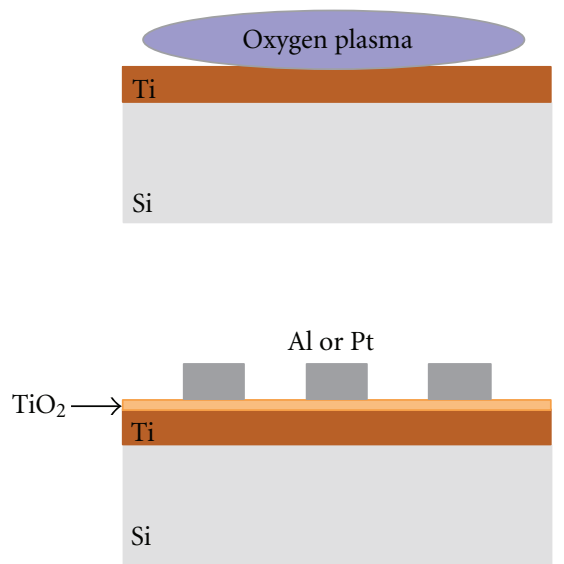

FIGURE 1: (a) process flow for native oxidized sample (left) and plasma oxidized sample (right). The top electrode was deposited by the shadow mask technique. The squares of sizes 200 microns, 100 microns, and 50 microns were deposited. (b) structure of MIM tunnel diode and its microscopic top view showing the Pt mesas of sizes $200 \mu \mathrm{m}, 100 \mu \mathrm{m}$, and $50 \mu \mathrm{m}$ squares.

or

$$
\begin{aligned}
G(V)= & {\left[G(0)\left(q^{2}\right)\left(\frac{9}{128} \frac{A_{0}^{2}}{\bar{\varphi}}\right)\right] V^{2} } \\
& -\left[G(0)(q)\left(\frac{A_{0}}{16} \frac{\Delta \varphi}{\bar{\varphi}^{3 / 2}}\right)\right] V+G(0),
\end{aligned}
$$

where $G(0)=\left(3.16 \times 10^{10}\right) \sqrt{\bar{\varphi}} t e^{-1.025 t \sqrt{\varphi}} ; A_{0}=4 \sqrt{2 m} t / 3 \hbar=$ $\left(1.2067 \times 10^{19}\right) t$.

In (2), $G(0)$ is conductivity at zero voltage, $m$ is effective mass of an electron in the $\mathrm{TiO}_{2}, \Delta \varphi$ is difference between potential barrier heights of the metals, $\bar{\varphi}$ is the average barrier height, $t$ is thickness of insulator, $\hbar$ is reduced plank's constant, $V$ is the applied bias voltage, and $q$ is charge of an electron.

Values of the coefficients in the parabola, given by (2), are calculated by fitting the experimental $d I / d V$ versus voltage plot to a parabola.

Performing some mathematical calculations with the parabolic fit to the experimental data, we get the thickness of the insulator is found to be $9 \mathrm{~nm}$, for both native and

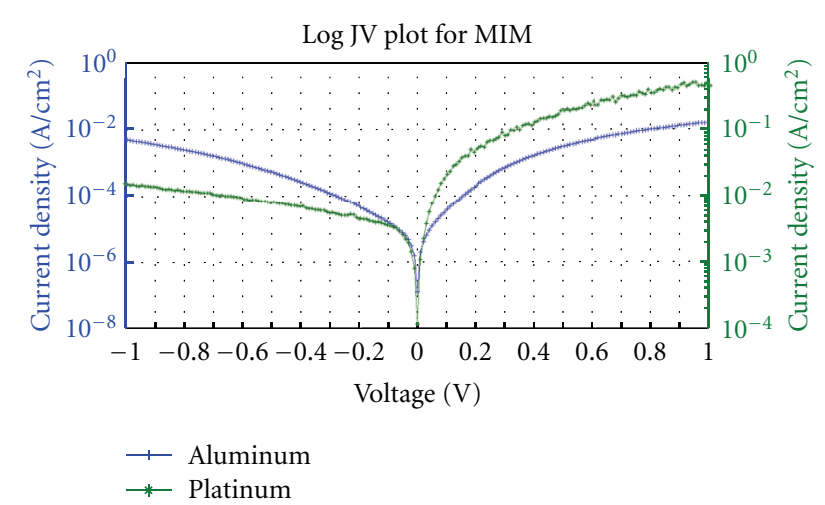

Figure 2: Current density versus voltage characteristics for Ti$\mathrm{TiO}_{2}$ (native)-Al and $\mathrm{Ti}-\mathrm{TiO}_{2}$ (native)-Pt MIM diode. (Logarithmic scale).

plasma oxide. It should be noted here that the absolute mass of an electron in titanium dioxide film is taken to be half of the electron mass. The asymmetry is also defined by the 


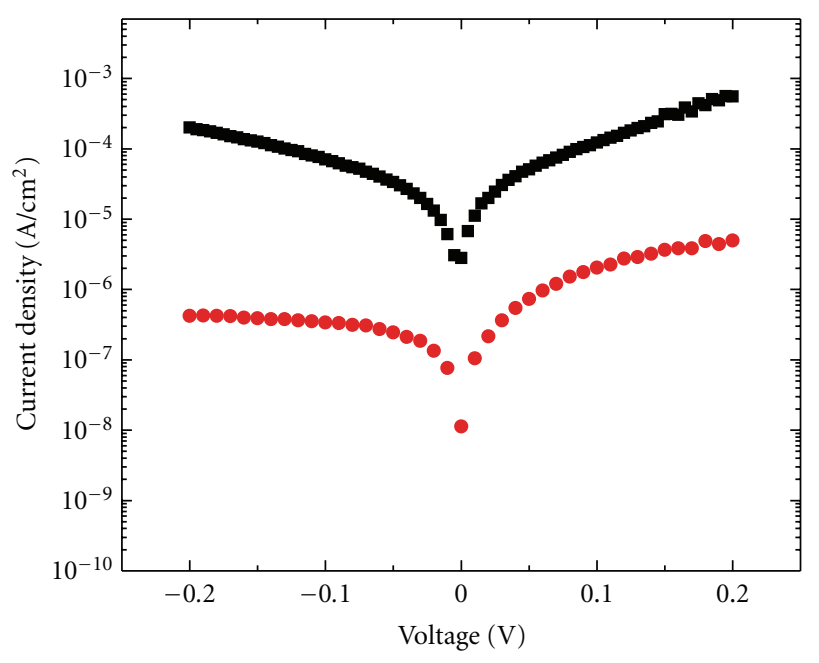

- Plasma-Pt

- Native-Pt

Figure 3: Comparison of current density (Logarithmic scale) of MIM Diodes made with native and Plasma $\mathrm{TiO}_{2}$.

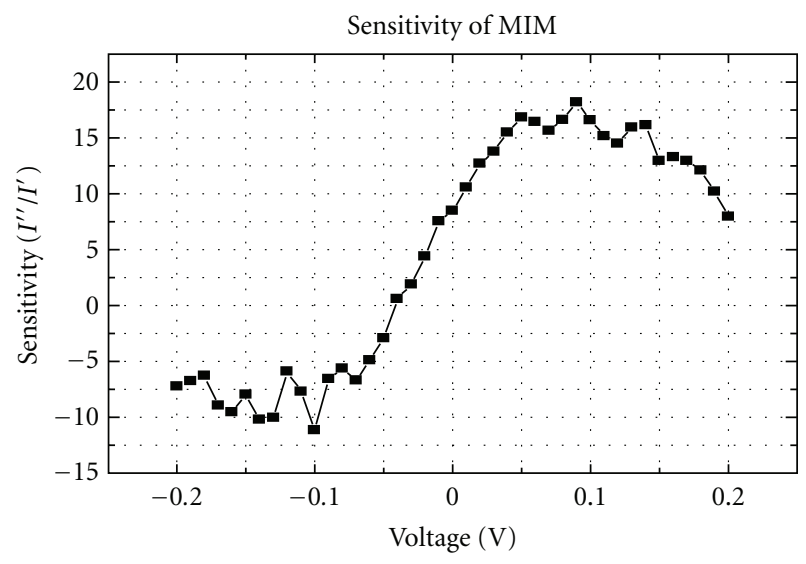

FIgure 4: Sensitivity of $\mathrm{Ti}^{-} \mathrm{TiO}_{2}$ (native)-Al MIM diode.

rectification ratio of the diode which is 15 at $0.495 \mathrm{~V}$ for plasma oxide, is more than reported in previous works. The rectification ratio for the native oxide is observed to be 6.5 at $0.33 \mathrm{~V}$. The plot for the rectification ratio is shown in Figures $7(\mathrm{a})$ and $7(\mathrm{~b})$.

As can be seen from Table 1, the sensitivity and the rectification ratio $\left(I_{f} / I_{r}\right)$ depend on the barrier thickness and the work function of the metals. According to (2) and by defining sensitivity $S=I^{\prime \prime} / I^{\prime}$, it is observed that sensitivity depends on parameters $A_{0}, \varphi$, and $\Delta \varphi$. Increasing work function difference will enhance sensitivity as it is also mentioned by Krishnan et al. [8]. Other factors are properties of insulator-metal interface such as trap density and oxide charges. In the presented work, we found that native $\mathrm{TiO}_{2}$ is able to provide better sensitivity. However, more studies and structure examinations are required to precisely explain the mechanisms of sensitivity improvement.

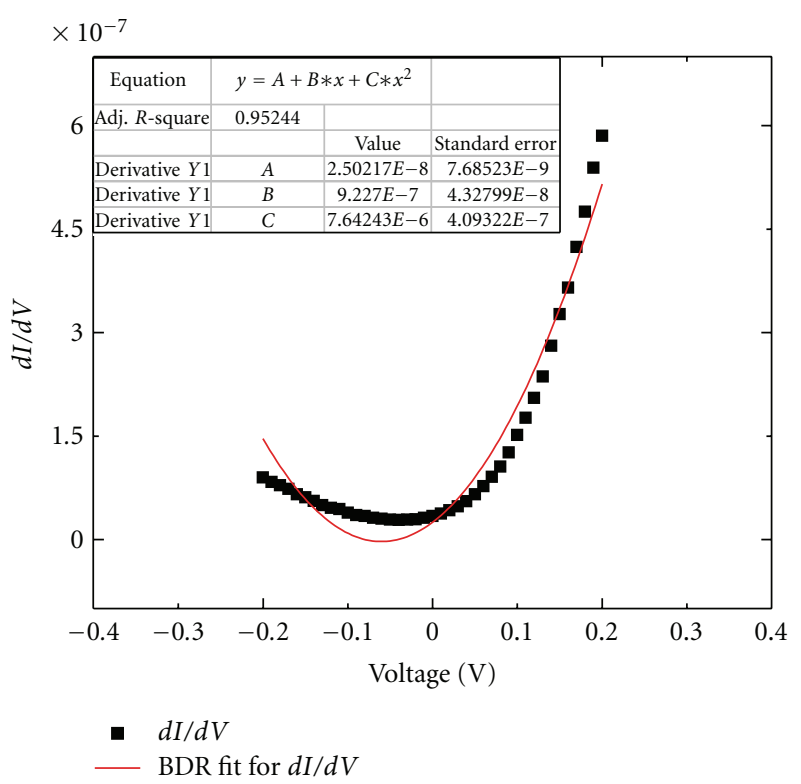

Figure 5: $d I / d V$ of $\mathrm{Ti}^{-\mathrm{TiO}_{2}}$ (native)-Al MIM diode with fitted parabola.

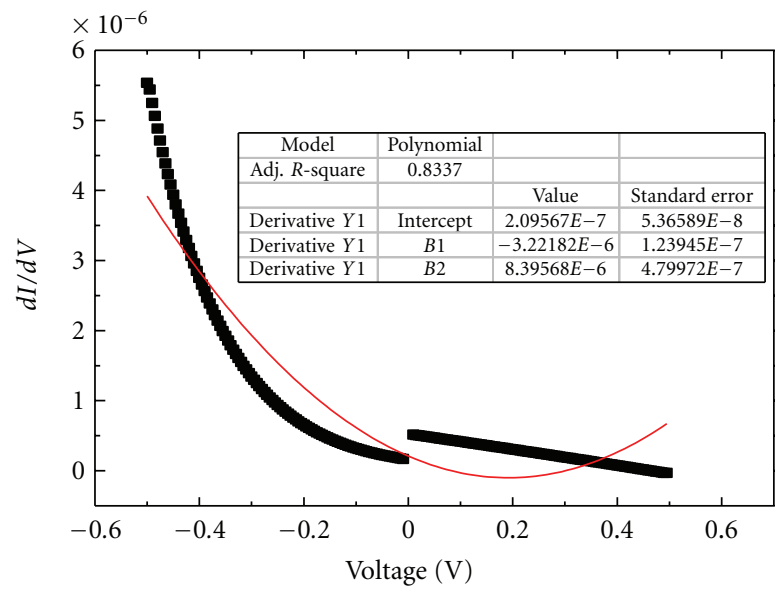

- $d I / d V$

— BDR fit for $d I / d V$

Figure 6: $d I / d V$ of $\mathrm{Ti}^{-} \mathrm{TiO}_{2}$ (plasma)-Pt MIM diode with fitted parabola.

\section{Conclusion}

This paper presents two different new MIM tunnel diodes: $\mathrm{Ti}^{-} \mathrm{TiO}_{2}$-Pt using plasma oxidization of $\mathrm{Ti}$ of which work function is $1.31 \mathrm{eV}$ less, compared to Pt work function and

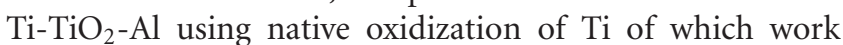
function is $0.27 \mathrm{eV}$ more, compared to $\mathrm{Al}$. Measurement results show that the diode with native $\mathrm{TiO}_{2}$ shows similar current densities but higher sensitivity as compared to the earlier reported work [11]. The plasma oxidation of $\mathrm{Ti}$ leads to higher current densities as compared to the MIM diode formed by native oxide. Parabolic conductivity plot confirmed the tunneling phenomenon. This parabola is used 


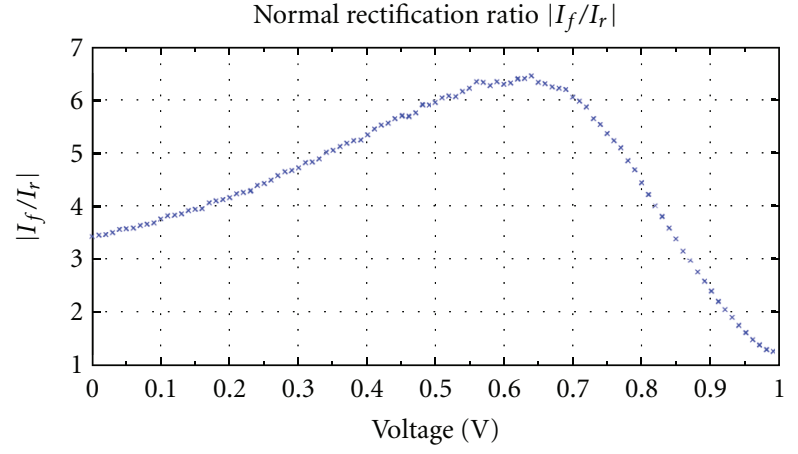

(a)

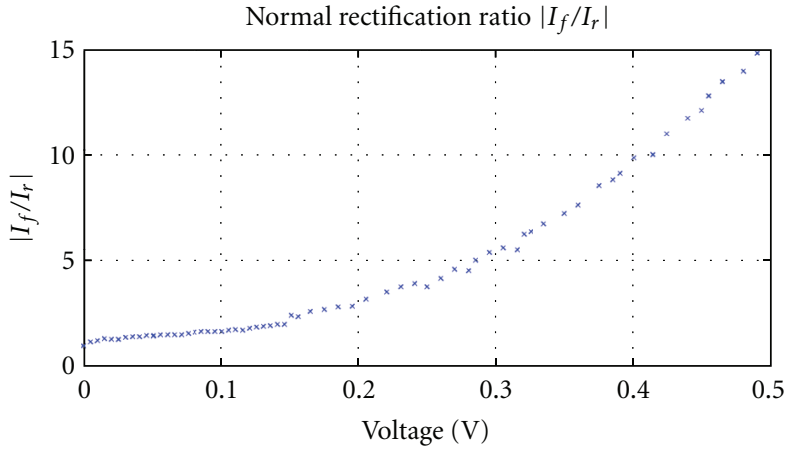

(b)

Figure 7: Rectification ratios $\left|I_{f} / I_{r}\right|$ plotted versus absolute value of voltages for (a) native oxide and (b) plasma oxide.

TABLE 1: Compares device characteristics of reported MIM diodes in the literature and this paper.

\begin{tabular}{|c|c|c|c|c|}
\hline Work & Type of mim diode & $\begin{array}{l}\text { Thickness of dielectric } \\
\text { (method of deposition) }\end{array}$ & Sensitivity $\left(\mathrm{V}^{-1}\right)$ & $I_{f} / I_{r}$ \\
\hline & Metal-insulator-metal & & & \\
\hline Hoofring et al. [7] & $\mathrm{Ni}-\mathrm{NiO}-\mathrm{Au}\left(0.64 \mu \mathrm{m}^{2}\right)$ & $2.2 \mathrm{~nm}$ (plasma) & 4.55 & 1.1 \\
\hline Krishnan et al. [8] & $\mathrm{Ni}-\mathrm{NiO}-\mathrm{Cr}\left(1 \mu \mathrm{m}^{2}\right)$ & $3 \mathrm{~nm}$ (reactive sputter) & 5 & $\sim 1.1$ \\
\hline Krishnan et al. [9] & $\mathrm{Ni}-\mathrm{NiO}-\mathrm{Cr} / \mathrm{Au}\left(100 \mu \mathrm{m}^{2}-1 \mu \mathrm{m}^{2}\right)$ & $3 \mathrm{~nm}$ (plasma) & NA & $4.5-6$ \\
\hline Krishnan et al. [10] & $\mathrm{Ni}-\mathrm{NiO}-\mathrm{Cr} / \mathrm{Au}\left(1 \mu \mathrm{m}^{2}\right.$ area $)$ & $3 \mathrm{~nm}$ (plasma) & 7 & \\
\hline Krishnan et al. [10] & $\mathrm{Ni}-\mathrm{NiO}-\mathrm{Cr} / \mathrm{Au}\left(100 \mu \mathrm{m}^{2}\right.$ area $)$ & $3 \mathrm{~nm}$ (plasma) & 15 & NA \\
\hline This work & $\mathrm{Ti}^{-\mathrm{TiO}_{2}}-\mathrm{Al}\left(21287 \mu \mathrm{m}^{2}\right.$ area $)$ & $9 \mathrm{~nm}$ (native) & 18 & 6.5 \\
\hline
\end{tabular}

to estimate the barrier thickness, which is around $9 \mathrm{~nm}$ for both diodes. Plasma oxidization can be optimized to get ultra thin oxide and hence high current density can be obtained. Ti and $\mathrm{Pt}$, due to their high work function difference prove to be a desirable choice for MIM tunnel diode. In spite of the same thickness, the higher current density for the plasma oxide can be explained by the higher work function of Pt compared to Al.

\section{Acknowledgment}

Financial support of National Center for Photovoltaic Research and Education at IIT-Bombay, funded by MNRE, Govt of India is gratefully acknowledged.

\section{References}

[1] D. K. Kotter, S. D. Novack, W. D. Slafer, and P. J. Pinhero, "Theory and manufacturing processes of solar nanoantenna electromagnetic collectors," Journal of Solar Energy Engineering, vol. 132, no. 1, pp. 0110141-0110149, 2010.

[2] M. Arrawatia, M. S. Baghini, and G. Kumar, "RF energy harvesting system from cell towers in $900 \mathrm{MHz}$ band," in Proceedings of the National Conference on Communications (NCC'11), Bangalore, India, January 2011.

[3] M. Arrawatia, M. S. Baghini, and G. Kumar, "RF energy harvesting system at 2.67 and $5.8 \mathrm{GHz}$," in Proceedings of the Asia-Pacific Microwave Conference Proceedings (APMC '10), pp. 900-903, Yokohama, Japan, 2010.
[4] M. Arrawatia, V. Diddi, H. Kochar, M. S. Baghini, and G. Kumar, "An integrated CMOS RF energy harvester with differential microstrip antenna and on-chip charger," in Proceedings of the IEEE International Conference on VLSI Design, Sister Conferences of DAC, Hyderabad, India, 2012.

[5] W. C. Brown, "The history of power transmission by radio waves," IEEE Transactions on Microwave Theory and Techniques, vol. 32, no. 9, pp. 1230-1242, 1984.

[6] R. L. Bailey, "A proposed new concept for a solar energy convertor," Journal of Engineering for Power, vol. 94, no. 2, pp. 73-77, 1972.

[7] A. B. Hoofring, V. J. Kapoor, and W. Krawczonek, "Submicron nickel-oxide-gold tunnel diode detectors for rectennas," Journal of Applied Physics, vol. 66, no. 1, pp. 430-437, 1989.

[8] S. Krishnan, H. La Rosa, E. Stefanakos, S. Bhansali, and K. Buckle, "Design and development of batch fabricatable metalinsulator-metal diode and microstrip slot antenna as rectenna elements," Sensors and Actuators A, vol. 142, no. 1, pp. 40-47, 2008.

[9] S. Krishnan, E. Stefanakos, and S. Bhansali, "Effects of dielectric thickness and contact area on current-voltage characteristics of thin film metal-insulator-metal diodes," Thin Solid Films, vol. 516, no. 8, pp. 2244-2250, 2008.

[10] S. Krishnan, S. Bhansali, E. Stefanakos, and Y. Goswami, "Thin film metal-insulator-metal junction for millimeter wave detection," Procedia Chemistry, vol. 1, no. 1, pp. 409-412, 2009.

[11] S. Krishnan, Thin film metal-insulator-metal junction for millimeter wave detection, Ph.D. thesis, University of South Florida, 2008. 
[12] N. F. Mott, "A theory of the formation of protective oxide films on metals," Transactions of the Faraday Society, vol. 35, pp. 1175-1177, 1939.

[13] N. F. Mott, "The theory of the formation of protective oxide films on metals, II," Transactions of the Faraday Society, vol. 35, pp. 472-483, 1940.

[14] N. F. Mott, "The theory of the formation of protective oxide films on metals," Transactions of the Faraday Society, vol. 43, pp. 429-434, 1947.

[15] N. Cabrera and N. F. Mott, "Theory of the oxidation of metals," Reports on Progress in Physics, vol. 12, p. 163, 1948.

[16] C. Adrianus, Plasma oxidation of magnetic tunnel junctions, Ph.D. thesis, Eindhoven University of Technology, 2005.

[17] W. F. Brinkman, R. C. Dynes, and J. M. Rowell, "Tunneling conductance of asymmetrical barriers," Journal of Applied Physics, vol. 41, no. 5, pp. 1915-1921, 1970. 

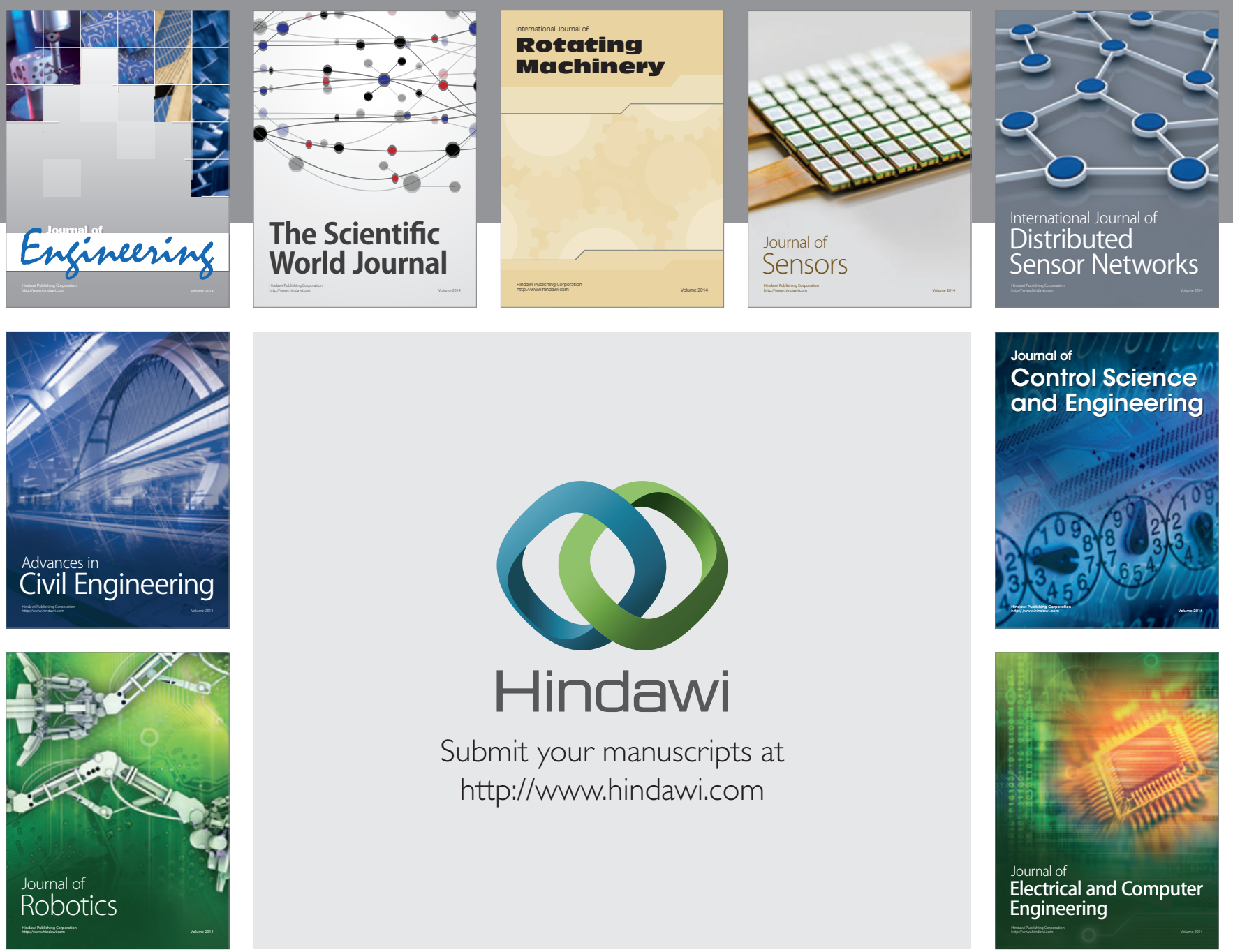

Submit your manuscripts at

http://www.hindawi.com
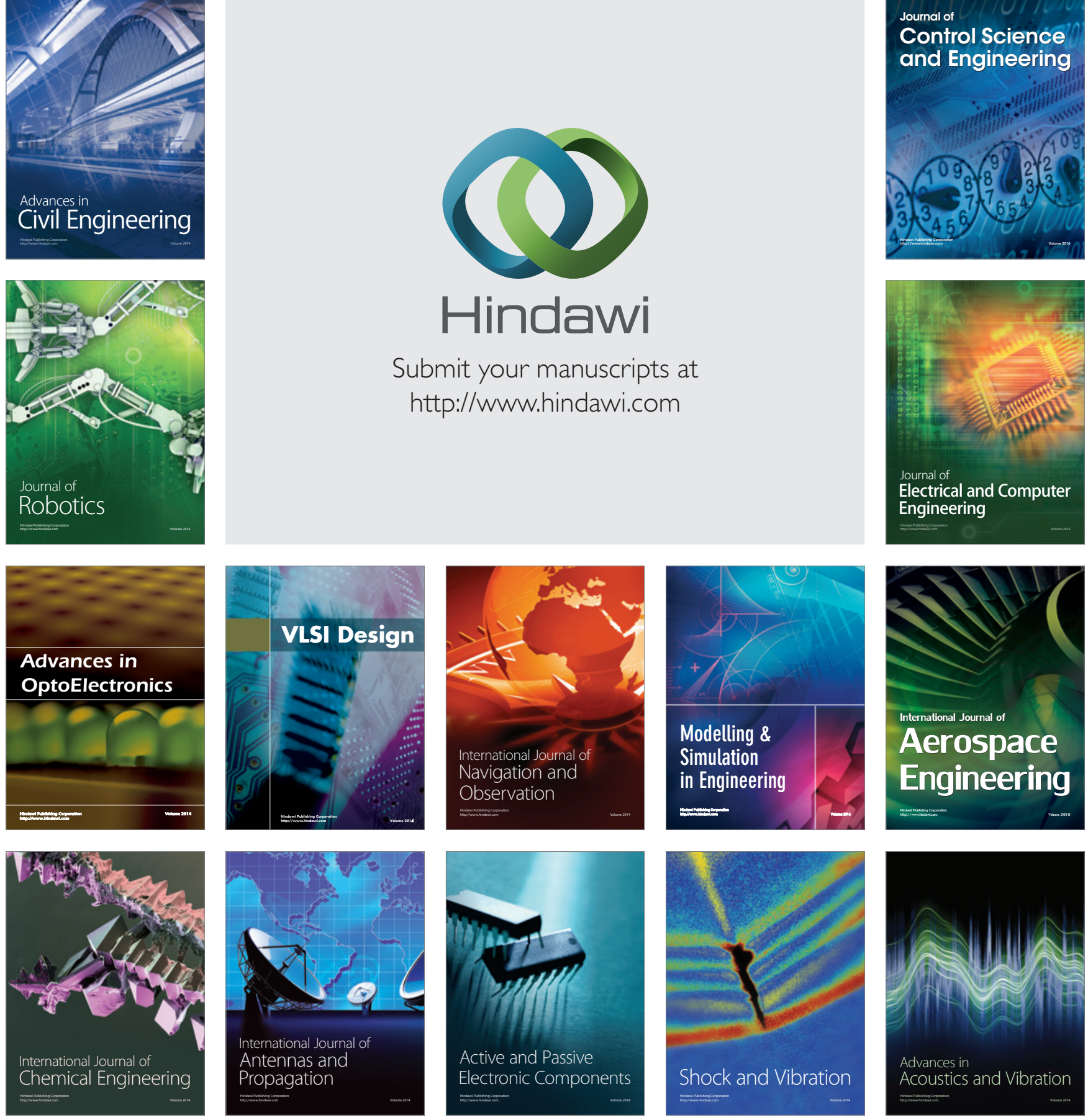